\title{
Infant Feeding Styles: Barriers and Opportunities for Good Nutrition in India
}

\author{
Patrice L. Engle, Ph.D
}

India has the lion's share of malnourished children in the world. Poverty and social exclusion contribute to this rate of malnutrition, but care practices also play a role. Breastfeeding is rarely exclusive, sanitation tends to be limited, complementary feeding often begins late, and the quantities are small. In the past, government programs have focused on the supply of food rather than caring practices. A research agenda will include both operational research on the nutrition programs, and formative and intervention research to improve caring practices, particularly those around infant and young child feeding.

\section{Malnutrition in India}

Despite India's progress over the decades, malnutrition continues to compromise too many of its citizens, especially those who are so vulnerable that they must rely on the auspices of others. The World Bank ${ }^{1}$ reported that in 1998 , India had $20 \%$ of the world's children, but $40 \%$ of its malnourished children, with almost a third of children born low birth weight. The data from the National Family Health Survey (NFHS) in 1998-1999 revealed a slight decrease from the 1992-1993 survey in the percent of children underweight, from $51 \%$ to $46 \%$, an average reduction of $0.8 \%$ per year. At this rate, India will not reach the goal of halving the rate of malnutrition until the year 2030, 30 years beyond the original goal for the year 2000 .

Micronutrient malnutrition continues to be a major issue. Although the percent of children with clinical signs of Vitamin A deficiency is dropping overall, in some areas it is still as high as $5 \% .^{2}$ Anemia, primarily owing to iron deficiency, has been seen as a problem among pregnant women, but recent data from the NFHS II survey report rates of anemia in young children of more than $74 \%{ }^{3}$ Iodine deficiency disorders appear to be

Dr. Engle is with the UNICEF Country Office, New Delhi, India 110-003. on the decline, but only $48 \%$ of households regularly consume adequately iodized salt. ${ }^{3}$

Why are malnutrition rates in India so hard to change? They are influenced by a whole variety of factors, including lack of health care, unsanitary conditions, lack of food, and poor caring practices. These factors are in turn influenced by a variety of social, cultural, and historic conditions, such as the status and marginalization of women. A common belief is that lack of food is the reason for malnutrition; however, it is only one contributing factor. Equally important are caring practices, such as infant and young child feeding, and the family resources needed to provide that care.

Ghosh ${ }^{4}$ has argued that the high rates of malnutrition in India are not primarily caused by poverty; rather, the behaviors of delayed initiation of breastfeeding, early introduction of water and liquids, and delay in complementary feeding results in a period of " perpetual hunger for the child." 4 This occurs "because the child was dependent on someone else to feed him/her and this person did not have the knowledge and awareness (or time) regarding how much food this child needed and how often."

\section{Infant Feeding Patterns}

NFHS I data, collected in 1992-1993, indicate that 51\% of women are exclusively breastfeeding from $0-3$ months. ${ }^{5}$ There is evidence of improvement; in the only state for which the new NFHS data were available at the time of this writing, Andara Pradesh, there were noticeable increases in the percent of women exclusively breastfeeding at 2-3, 4-5, and 6-7 months of age (Figure 1). Although India is a country very supportive of breastfeeding, truly exclusive breastfeeding is quite uncommon, as mothers begin to supplement with top milks and water in the child's first months. Some studies have shown rates of $3 \%$ or less $^{6}$ when a more rigorous definition of exclusive breastfeeding is used than the NFHS II. Since it is widely assumed that water is necessary for children, mothers tend not to consider water when asked whether they are giving any other foods or fluids to their child, unless specifically asked. 


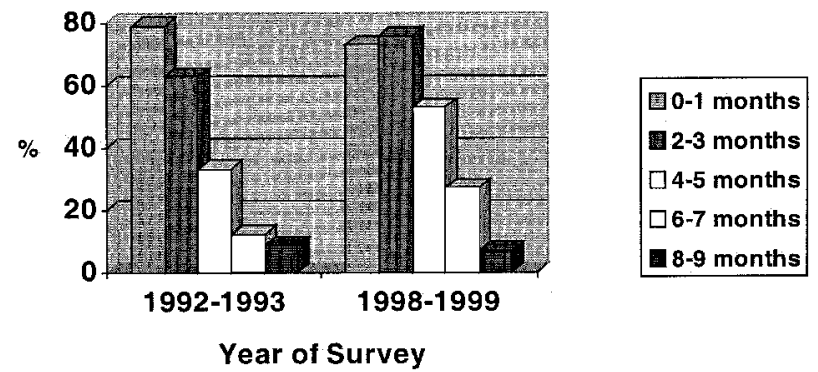

Figure 1. Rates of exclusive breastfeeding by age of child: Andara Pradesh. Source: references 3 and 5.

Indian data, in general, show very delayed introduction of complementary foods. According to the 1992-93 NFHS data, only $31 \%$ of children $6-9$ months of age were receiving foods other than breast milk, although they were receiving water and other liquids. Figure 2 shows the percentage of children given complementary food by age in India. The data from 1998-1999 have improved little; $33 \%$ of children are reported to receive foods other than breast milk from 6-9 months. Figure 3 shows that the median age at introduction of complementary foods (approx 10 months) does not vary by urban/rural residence but does vary by education level of the mother, dropping when she has some primary education.

\section{Dimensions of Feeding Behavior}

Even though food may be limited in many families, providing food is not enough. Gains owing to improved food intake will be lost without improved use of sanitation systems, increased preventive health care, reduction of other causes of poor nutrition such as excessive wormloads, and appropriate breastfeeding and childfeeding practices. These are all caring practices that are performed on a daily basis by mothers and other caregivers. We must recognize the importance of these care practices. Without changing these practices, it will be difficult to affect nutrition status.

Providing good care requires resources from the caregivers-knowledge and skills, time, economic re-

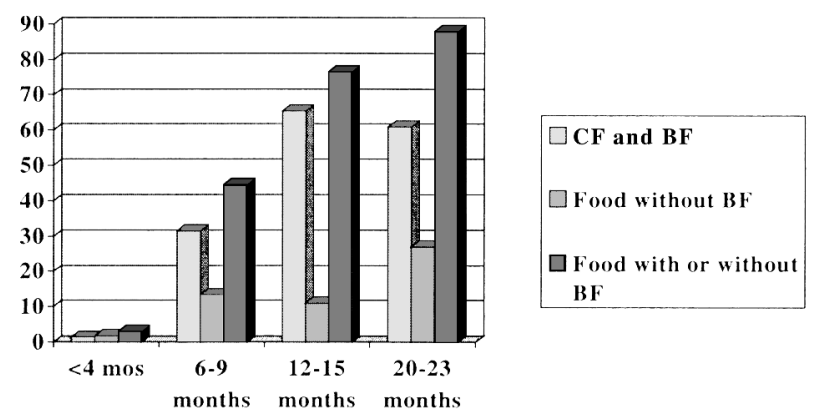

Figure 2. Percentage of children given complementary food by age: India. Source: reference 5. CF $=$ complementary food, $\mathrm{BF}=$ breastfeeding.

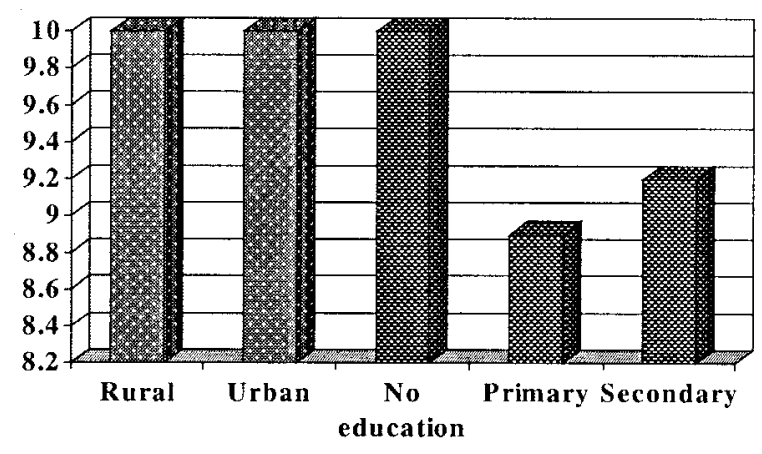

LOCATION MOTHER'S EDUCATION

Figure 3. Median age at introduction of complementary foods: India. Source: reference 5.

sources, and control of decision-making. Families and mothers need the ability to make decisions about caring for their children, such as making timely decisions about seeking health care. Resources also depend on the policies of government to develop services and policies that strengthen families' ability to provide care.

Feeding is one of the most time-consuming and least well-understood caring practices, with critical effects on child nutrition status. Good complementary feeding behavior has three components: 1) adapting the feeding method to the child's psychomotor abilities (e.g., spoon handling); 2) feeding responsively, including feeding when the child is hungry, encouraging a child to eat, recognizing possible low appetite, balancing child versus caregiver control of eating, and using an affectionate or warm style of relating to the child during feeding; and 3) creating a satisfactory feeding situation by reducing distractions, developing a consistent feeding schedule, and supervising and protecting children during eating.

The care practices during feeding often appear together in patterns that can be considered to represent on overall "style" of feeding. Three feeding styles have been identified: controlling, laissez-faire, and responsive. Each of these feeding styles has roots in cultural beliefs systems and parental theories (ethno-theories) of appropriate behavior. These terms for feeding styles were introduced by Birch and Fisher ${ }^{7}$ and have been further developed by Bentley et al. ${ }^{8}$

In a highly controlling style of feeding, the caregiver has complete control of when and how much the child eats. In some cases, this control may result in forced feeding. Under these circumstances, children may be unable to develop mechanisms for learning to regulate their intake. This style of feeding has been observed to be common in Nigeria. ${ }^{9}$ It also appears in industrialized countries such as the United States. Johnson and Birch ${ }^{10}$ found that in the United States, parental pressure for a child to eat regardless of her hunger is a precursor of later obesity for girls, though less so for boys. Thus these 
behavioral aspects of feeding may have relevance not only for undernutrition, but also for obesity.

In a laissez-faire style, the caregiver makes little effort to encourage eating, and may often expect that children should eat without assistance at an early age. These attitudes may reflect the belief that children know best how much they should eat. Parents may say that the child's "stomach knows its limits." These attitudes may be detrimental when children have low appetites.

Finally, a caregiver with a responsive or interactive feeding style responds to the child's hunger cues in reasonable time, feeds using strategies of encouragement and praise, feeds in a consistent manner, and feeds more actively when the child is recovering from an illness. These behaviors are presumed to help the child develop an internal mechanism for regulating food intake.

\section{Research Evidence for Feeding Styles}

Several studies in Latin America have identified a laissez-faire style of feeding, with more responsive feeding observed only when the child's intake drops because of illness. Engle and Zeitlin ${ }^{21}$ studied 80 children ages 12-18 months in low-income areas of urban Nicaragua. Figure 3 shows the number of eating events in which particular strategies were used. Many strategies were relatively infrequent-only about $10 \%$ of mothers demonstrated or modeled eating, threatened, offered more food, or told the child to eat an additional food. The majority encouraged eating verbally, although $40 \%$ made no verbal comments about eating during the meal. The most common encouragements were orders such as "eat your food."

Surprisingly, better-nourished children did not receive more encouragement. ${ }^{21}$ Caregivers were more likely to encourage eating only during meals in which children refused food, suggesting that the encouragement was a response to low intake and was not proactive. Thus it is not surprising that there was no association between parental encouragement and child nutrition status. Child interest in food was, however, associated with children's nutrition status.

On the other hand, the mother's belief that she could and should do something to help a child eat more was associated with better nutrition status, even controlling for maternal education and family wealth. ${ }^{21}$ This parental "ethno-theory" was measured with a simple threequestion scale assessing the age at which she thought that children should be able to eat alone (41\% said that they could do this at 12 months), whether she would offer additional food if the child refused food, and whether she thought that there were things one could do if a child was uninterested in eating.

Two studies in rural Guatemala and rural Peru by Bentley et al. ${ }^{12,13}$ also found laissez-faire feeding styles to be predominant. In Peru, among caregivers in the rural Sierra, no encouragement or responsive feeding was shown in $70 \%$ of the feeding episodes. More encouragement was observed during illness episodes. In rural Guatemala, a similar lack of encouragement or responsivity was seen when children were "healthy." Caregivers showed more responsive patterns of feeding when children had persistent diarrhea.

Is a laissez-faire feeding style, with increased encouragement limited to illness episodes, acceptable for these children? We suggest that it is not, since these behaviors were observed in populations with a high percentage of stunting. Intake is probably limited by low appetite even when children are not ill. Also, the probable poor quality of the diet means that children may not eat enough unless given considerable encouragement. However, we do not know at this time whether using more responsive feeding strategies would be sufficiently powerful to increase intake significantly. To answer this question, a randomized controlled trial is needed.

\section{Factors Influencing Delayed Introduction of Complementary Foods in India}

Beliefs can influence the timing of the introduction of complementary foods. Although there are many reasons for this delay, including income level and education, one study of poor families in five states reported that mothers delayed because they perceived that the child is not interested. Mothers and grandmothers reported that one should wait until the child shows hunger before giving any kinds of foods, suggesting that the perception of a child's hunger can play a major role. ${ }^{19}$

One formative research study by the Academy for Educational Development in Uttar Pradesh identified behavioral practices in breastfeeding and complementary feeding that could reduce intake of complementary foods. ${ }^{14}$ As noted earlier, the mothers in the study all valued breastfeeding on demand. However, breastfeeding initiation was delayed in almost all cases (more than $50 \%$ did not begin for 48 hours), prelacteal foods were usually given, exclusive breastfeeding only continued through the second month, and feeds were generally short, not even emptying one breast.

Factors identified by researchers as reducing the intake of complementary foods include late introduction of complementary foods, using food as a "distracter" rather than as an element of the diet, and a belief that children less than 12 months of age cannot digest adult food. From 6 to 9 months of age, children received only $114 \mathrm{kcal} / \mathrm{day}$, resulting in a deficit of $167 \mathrm{kcal} /$ day. Finally, from 9 to 11 months of age the children's diets were short by more than $200 \mathrm{kcal} / \mathrm{day}$.

Interventions can be effective. Hahjeboy and team ${ }^{14}$ performed household trials in the villages selected to 
improve rates of breastfeeding and complementary feeding. Results showed that the most effective messages about breastfeeding were telling the woman to give longer breastfeeds, to empty each breast (when the benefits of doing so were explained), and to stop giving "top milk" or animal milks. Mothers reported that the amount of breast milk that they had available had increased when they followed these recommendations.

In the household trials, several messages regarding complementary feeding were found to be effective. Mothers were willing to give higher nutrient density food, and reported that babies were happier, more active, and allowed the mother more time for her work. Mothers were also willing to give family food, as opposed to special food, to the child because it did not take additional time.

\section{Barriers to Good Infant and Young Child Feeding in India}

A major barrier to good child nutrition is a general belief that the major cause of malnutrition is lack of food, rather than lack of feeding or other care practices. Feeding, as well as sanitation and hygiene, practices contribute to the steep decline in weight during the first year of life.

Second, many beliefs that are regionally held affect all aspects of feeding, such as food taboos, beliefs about when and how one can introduce complementary foods, beliefs about birth, etc. These beliefs have to be recognized and incorporated into communication strategies in order to build on traditional practices, some of which are positive. Beliefs about breastfeeding patterns (e.g., not breastfeeding while cooking since the milk gets hot and not beginning to offer breast milk until the sister-in-law puts the breast on the child's mouth) ${ }^{15}$ need to be documented and understood.

Third, India's major nutrition intervention program may be less effective than it could be. India has the largest program in the world addressing problems of malnutrition and child development, the Integrated Child Development Services (ICDS). The program began in 1975, and now covers almost all of the low-income blocks in India. This program provides six main services to children through a village worker (anganwadi worker) who is paid a small honorarium, not a salary. Children are helped to get immunizations and health checkups, pregnant and lactating women receive counseling and additional food, children's growth is monitored on a regular basis, children are given a preschool education, and supplementary food is provided five days a week. Adolescent girls are also supported.

Much has been written about this program over the past 25 years, but until recently the model has not changed. Evaluation research has shown that it has pos- itive effects on school attendance and age of school entry, as well as immunization rates and prevalence of severe malnutrition, but evidence for effects on overall nutrition status is limited. This is not surprising since the food is primarily given to children 3 to 6 years of age, when relatively little effect might be expected.

One of the barriers to good nutrition has been the inability of the system to reach pregnant and lactating women and children under three years of age. However, new initiatives under the governmental leadership and World Bank funding are trying to increase the focus on these groups.

Funds allocated by the government for nutrition may not be spent in the most effective way. The ICDS program spends a tremendous amount on food, but in many areas food is not the limiting factor. Growth monitoring occurs, but in many places there is no promotion, and in fact, the mother is not even informed about the results of the monitoring. The worker collects a large amount of data on her villages, all of which goes into a central system and often is not used to give her feedback as to the success of her efforts. Because this system deals with nutrition, the health system plays a negligible role in nutrition counseling. Previously the model was the same across the country, and did not deal with local variations. Recently there are substantial efforts to allow for more local control and local variation.

In addition to poverty and social marginalization, the status of women may be an underlying variable explaining the Asian Enigma; children are better nourished in most African countries than in South Asia, even though incomes are similar. ${ }^{16}$ The authors suggest that the lower status of South Asian women affects not only their care practices, but also their ability to provide care-they may have less autonomy in decision-making, less control over time and resources, and lower access to resources, health, and nutritional well-being. In many families the key decision maker is not the mother but the parents-in-law, and targeting the mother for behavior change may be ineffective. Other family members must also be involved in behavior change. Improving family care for women and girls needs to be a key intervention.

Finally, the effects of social changes such as urbanization (expected to reach as much as $50 \%$ in some states of India in the next 10 years) may undermine good nutrition. As families change, become more urbanized, and move from place to place, they lose traditional practices, negative as well as positive ones. It is critical to support these practices when they are positive.

Women are increasing their work for income around the globe, particularly in the early years of their children's lives. ${ }^{17}$ Women's need to work for earnings when children are infants, and their associated poverty, often puts children at risk of poor nutritional status. Although 
studies generally do find that women's work for earnings contributes to shorter duration of breastfeeding, there are many mothers who can continue to breastfeed despite working outside of the home. Work is often not cited as the reason for stopping breastfeeding. Aggarwal et al. ${ }^{18}$ reported that perceived breast milk insufficiency, often based on the crying of the infant, was the most commonly cited reason for supplementing breast milk among low-income urban women in Delhi. These women began top feeds (nonhuman milks, usually highly diluted and prepared without proper hygienic conditions) before 4 months of age. Insufficient milk was cited more often than needing to work or lack of childcare as the reason for supplementing breast milk.

Many evaluations of the nutrition status of Indian children emphasize the need for childcare or daycare for the young children of working mothers. ${ }^{19,20}$ Despite large government programs to support food distribution, these daycare needs are not met. Although one might think that children raised in a joint family would have a better chance for good nutrition status, data do not always support that hypothesis. ${ }^{19}$ An extensive review of studies relating childcare time to children's nutrition status found that most studies did not find a simple association between increased time in child care and improved nutrition status. ${ }^{11}$ More important factors appeared to be the woman's rate of pay, her control of her income, the flexibility of her work situation and the adequacy of alternate childcare (resources for care).

\section{Research and Action Agenda}

The research agenda should focus on formative research into variations in feeding practices, and beliefs supporting those practices, in the various regions of India. These investigative studies should be followed by intervention research on changes in feeding practices and care behaviors. Intervention studies, then, can be used to develop improved behavior change strategies. Effectiveness of components of interventions needs to be compared. Is it cost-effective to include deworming, hand pumps, and hygiene information with a complementary feeding intervention? To what extent is the quality of the complementary food a critical factor? Should micronutrients be added to complementary food in addition to feeding interventions?

There is also a need for operational research. How the quality and implementation of existing nutrition programs can be improved within the constraints of government budgets needs to be explored. The system to provide feedback to community workers and community elected bodies needs to be developed. Care and feeding practices need to be more explicitly targeted as interventions in health and ICDS systems. Growth monitoring needs to be improved and promotion made a stronger component. Communities need to be made aware of the number of malnourished children in the community so that they can take an active role in helping rates decline. Finally, links between programs should be strengthened so that the multiple government workers in each area are working together to improve the nutrition status of India's children.

1. World Bank. India wasting away: the crisis of malnutrition in India. New Delhi World Bank, 1998

2. Department of Women and Child Development, Ministry of Human Resource Development, Government of India. India nutrition profile. New Delhi DWCD, GOI, 1998

3. International Institute for Population Sciences. National family health survey (NFHS-2). India report. Mumbai: IIPS, 1999

4. Ghosh S. Integrated child development services programme-need for reappraisal. Indian Pediatr 1997;34:911-8

5. International Institute for Population Sciences. National family health survey (NFHS). India report. Mumbai: IIPS, 1993

6. Philips N. Early child feeding practices in Maharashtra, India: relationship with child growth and maternal time allocation [Dissertation]. Tufts University. 2000

7. Birch LL, Fisher A. Appetite and eating behavior in children. Pediatr Clin North Am 1995;42(4):931-53

8. Bentley MB, Engle PE, Caulfield L, et al. Caregiver style of infant feeding as a determinant of dietary intake: the need for promotion of "interactive feeding." FASEB J: Abstract 356.2, 1999

9. Brown KH, Dickin KL, Bentley MD, et al. Consumption of weaning foods from fermented cereals: Kwara State, Nigeria. In: Alnwick D, Moses S, Schmidt OG, eds. Improving young child feeding in Eastern and Southern African household-level food technology: proceedings of a workshop in Nairobi, Kenya, October 12, 1987. Ottawa, Canada: IDRC, 1988:181-97

10. Johnson SL, Birch LL. Parents' and children's adiposity and eating style. Pediatrics 1994;94(5):653-61

11. Engle PL, Menon P, Haddad L. Care and nutrition: concepts and measurements. World Development 1999;27(8):1309-38

12. Bentley M, Stallings R, Fukumoto M, Elder J. Maternal feeding behavior and child acceptance of food during diarrhea episodes, convalescence, and health in the Central Northern Sierra of Peru. Am J Public Health 1991;83:1-15

13. Bentley M, Caulfield L, Torun B, et al. Maternal feeding behavior and child appetite during acute diarrhea and subsequent health in Guatemala. FASEB J 1992;6:A436

14. Keith N, Hajeebhoy N. Breastfeeding, complementary feeding practices of children under 1 year (technical report), Sehaspur Block, U.P., India: qualitative research and field trials. Mimeo: AED, New Delhi 1998

15. Khera S. Internship report. Field Report to UNICEF, India: New Delhi, India, UNICEF, 2001

16. Bamalingaswami V, Jonsson U, Rohde J. Commen- 
tary of nutrition, progress of nations. NY: UNICEF 1996; 10-17

17. Engle PL. Women's work and child care. IFPRI series on urban food security and nutrition. 2020 project. Washington DC: International Food Policy Research Institute, 2000

18. Aggarwal A, Arora S, Patwari AK. Breastfeeding among urban of low socioeconomic status: factors influencing introduction of supplemental feeds before four months of age. Indian Pediatr 1998;35:269-73

19. Chirmulay D, Bhagwat IP. Factors influencing nutri- tional status of preschool children from selected areas in five states of India. Report No. IHPP/1. Pune, India: BAIF Development Research Foundation, 1997

20. Udipi SA, Merchant SS. Childcare and nutrition in India. Bombay: Department of postgraduate studies and research in home science, SNDT Women's University, 1995

21. Engle PL, Zeitlin M. Active feeding behaviour compensates for low child demand among Nicaraguan one-year-olds. J Nutr 1996;126:1808-16 